\title{
Student Perceptions of Their Learning Experience in Streamed and Mixed-Ability Classes
}

\author{
Paul Joyce \\ Kinki University, Japan \\ pauljoyce@hotmail.com \\ Brian McMillan \\ Kanda University of International Studies, Japan \\ peibrian@gmail.com
}

\begin{abstract}
Many foreign and second language programs place students in streamed classes according to their level of proficiency in the target language in order to allow teachers to better tailor lessons to the ability level of their students. On the other hand, it is argued that in mixed-ability classes, both higher- and lower-proficiency learners can benefit from peer tutoring and that lower-proficiency learners feel less stigmatized. While numerous studies have examined the effects of streaming in other contexts, few studies have been conducted to date within the context of L2 learning. Following a review of the relevant literature, this paper reports the results of a survey exploring the perceptions of first-year university students regarding their learning experiences in streamed and mixed-ability EFL classes. After considering a number of topical issues connected to student effect, the study concludes that there are advantages to streaming for both lower and higher proficiency students.
\end{abstract}

Walqui asserts that "a basic educational principle is that new learning should be based on prior experiences and existing skills" (2000, p. 3). With this in mind, many foreign and second language programs stream students according to their level of ability in the target language (TL). Jones, Harris, and Putt define streaming as "the practice of dividing up a group of students on the basis of previous educational experience or achievement, and subjecting the different subgroups to different educational experiences" (1990, p. 21). Through the creation of relatively homogeneous classes, teachers can more easily design activities that suit the proficiency level of their students (Ansalone, 2003). However, advocates of mixed-proficiency classes believe that teachers can meet the needs of each learner by providing differentiated instruction (Burris \& Garrity, 2008), and that students can also be supported in their learning through peer tutoring. It is also argued that streaming may have a stigmatizing effect on lower-proficiency learners, potentially leading to demotivation.

\section{Literature Review}

Socio-affective effects. All groups, whether streamed or multi-level, first go through a "forming" stage during which learners try to find their place in the class "hierarchy" (Dörnyei \& Murphey, 2003, p. 14). EFL learners often compare themselves to their peers, "many of whom appear to

Language Education in Asia, 2010, 1(1), 215-227. http://dx.doi.org/10.5746/LEiA/10/V1/A18/Joyce_Mcmillan 
be more competent and proficient" (Dörnyei \& Murphey, 2003, p. 15). We might expect, then, that this forming stage would be more stressful for lower-proficiency learners in mixed-ability classes who find themselves working alongside highly proficient classmates. Yet at the same time, stronger students may conceal their more advanced skills for fear of being viewed as show-offs or "nerds" (Dörnyei \& Murphey, 2003, p. 36). Students may affect a strong L1 accent, since speaking like a native speaker may be viewed as a sign of no longer belonging to one's L1 peer group (Walqui, 2000; Lefkowitz \& Hedgcock, 2002).

One argument often made against streaming is that students placed in lower-ability classes may develop inferiority complexes, leading to demotivation. In fact, research findings have been mixed. Liu, Wang, and Parkins (2005) suggest that for streamed students who understand the streaming process, across-group comparisons are strongest immediately after placement, since learners do not yet have any basis for comparing themselves with their classmates. Thus, students placed in lower-ability streamed classes may initially form a more negative academic self-concept. However, Liu et al. (2005) found that lower-ability students had a more positive academic self-concept than their higher-ability counterparts three years after placement. This reversal might be attributable to a more competitive classroom environment in higher streams, while students in lower streams may have more opportunity to experience success, consistent with the big-fish-little-pond (BFLP) effect.

A long list of studies have examined the BFLP effect (see Marsh, 1987), which predicts that students in higher-achieving schools or programs will tend to develop lower academic self-concepts as they compare themselves with more able peers. However, the BFLP effect is likely to be smaller for older students, as they are better able to assess their own skills in comparison with their classmates. Dai and Rinn (2008) also point out that students who do not compare favorably with others may employ coping strategies, such as making fewer comparisons or shifting their comparison targets. Upward social comparisons can also have positive effects if learners identify with more-able peers and believe that they can catch up through their own efforts (Murphey \& Arao, 2001).

Learner-learner interaction. Mathews-Aydinli and van Horne (2006, p. 1) suggest that in multi-level classes, "those with limited proficiency have an opportunity to interact with more proficient English speakers, and advanced learners benefit by using their English skills to help lower level students negotiate meaning." Indeed, several studies support the idea that different-proficiency pairs can collaborate effectively. Storch (2001) analyzed the interaction patterns of three pairs of students and found that the most collaborative pair was also the pair with the greatest proficiency difference (low and upper intermediate), while the pair which was closest in terms of proficiency (low and intermediate) interacted in a non-collaborative fashion. Watanabe (2008) found that three adult Japanese English language learners preferred working with partners who "shared many ideas" and concluded that "proficiency differences do not seem to be the decisive factor in affecting the nature of peer assistance" (p. 627). However, it stands to reason that a learner's ability to cooperate and contribute meaningfully while working on a collaborative task is closely tied to proficiency (Lesser, 2004) - especially if learners are expected to use the TL exclusively.

On the other hand, Mathews-Aydinli and van Horne (2006, p. 2) point out that "students with lower language skills and those who are generally less vocal may naturally segregate themselves from the more outspoken or advanced-level students." Indeed, learners at different proficiency levels do not always collaborate effectively as they may be reluctant to engage in negotiation for meaning, which they may view as "painstaking, frustrating, and face-threatening" (Eckerth, 2009, p. 121). 
Streaming in EFL programs at Japanese universities. Hitherto, few studies have examined teacher and student perspectives on streaming within the context of L2 learning. Gillis-Furutaka and Sakurai (2002) surveyed English learners and teachers regarding the implementation of a streaming system at a Japanese university. Most students and teachers viewed the new streaming system positively. However, it is difficult to interpret some of the reported results: $34.9 \%$ of students said that being with other students they could work well with was the "most important" factor to them in their English lessons, while being with students of the same level of ability or motivation was most important for $18.7 \%$ and $19.9 \%$, respectively. Similar to the point made earlier about Watanabe's (2008) findings, there could be a connection between "level of ability" and "ability to work well with."

Mills, Swain, and Weschler (1996) reported on the implementation of a streaming system at another Japanese university. They contend that participation and the class dynamic may suffer in mixed-ability classes, particularly in Japanese contexts where it has often been noted that "the nail that sticks out gets hammered down" (p. 1); they also note that there is still enough variation left within streamed classes to allow for peer assistance.

To further investigate the debate over streaming in the EFL/ESL context, a questionnaire was used to address the following research questions:

1. How do the classroom learning experiences of students in streamed classes compare with those of students in mixed-ability classes?

2. How do the classroom learning experiences of higher proficiency students in streamed classes, lower proficiency students in streamed classes, and students in mixed-ability classes compare?

\section{Methodology}

\section{Context and Participants}

The research was undertaken at a Japanese university specializing in foreign languages. All participants in the study were enrolled as full-time English language major undergraduates in their first year of study. The students could broadly be described as being at a false beginner to an intermediate level and would be expected to score between around 70 and 180 on the TOEFL Computer-Based Test (Bonk, 2001). The participants were drawn from the English and International Communication (IC) departments, which share similar communicative proficiency goals, course content, and class sizes of around 25. Teachers and students in both departments are officially expected to follow an English-only policy.

Students from both departments were placed into their first-year classes based upon their performance on the same in-house general proficiency measure. In the English department, learners were divided into four proficiency streams; these were sub-divided to form relatively homogeneous streamed classes. IC department students were placed into mixed proficiency classes with a fairly equal distribution of high, intermediate, and lower-proficiency students.

\section{Research Design}

A questionnaire, translated into Japanese by a paid translator, was distributed to students in six streamed classes and six non-streamed classes. Of the streamed classes, surveys were completed by three classes from the most proficient of the four ability bands, and three classes from the lowest band. The survey contained 10 statements that relate to aspects of student effect (see Appendix). Participants responded on a four-point bipolar scale (strongly agree, agree, disagree, and strongly disagree). For the purposes of the statistical analyses, the feedback was converted into an interval scale from one (strongly agree) to four (strongly disagree). Students' year-end proficiency test scores were also employed in this study. The proficiency test was a 
norm-referenced, general proficiency test of English as a foreign language that included reading, writing, listening, and speaking sections (Cronbach's $\alpha=.85$ ). The questionnaire was administered approximately two weeks before the proficiency test, at the end of the participants' first year at the university.

\section{Results}

\section{Sample}

In total, there were 266 students involved in the study. However, after the listwise removal of missing data, the research population was reduced to 242 participants. Table 1 presents an overview of the students' year-end performance on the proficiency test. The scores have been placed onto a standardized scale with a mean of 500 and a standard deviation (SD) of 100. The proficiency results for non-streamed $(n=107)$ and streamed students' $(n=135)$ results have been separately reported. In addition, within streamed classes, the scores from the high classes $(n=75)$ and low proficiency classes $(n=60)$ have been sub-divided.

\section{Table 1}

\section{Standardized Proficiency Scores for Streamed and Unstreamed Groups}

\begin{tabular}{|c|c|c|c|c|c|c|c|}
\hline Group & Subgroup & $\boldsymbol{n}$ & Reading & Writing & Listening & Speaking & Overall \\
\hline Unstreamed & Combined & 107 & $\begin{array}{c}495 \\
(87.6)\end{array}$ & $\begin{array}{c}505 \\
(92.1)\end{array}$ & $\begin{array}{c}482.4 \\
(97.4)\end{array}$ & $\begin{array}{c}479 \\
(89.5)\end{array}$ & $\begin{array}{c}488 \\
(87.5)\end{array}$ \\
\hline Streamed & Combined & 135 & $\begin{array}{c}504 \\
(109.0)\end{array}$ & $\begin{array}{c}496 \\
(106.0)\end{array}$ & $\begin{array}{c}514 \\
(100.2)\end{array}$ & $\begin{array}{c}517 \\
(104.9)\end{array}$ & $\begin{array}{c}510 \\
(108)\end{array}$ \\
\hline Streamed & High & 75 & $\begin{array}{c}562 \\
(78.9)\end{array}$ & $\begin{array}{c}558 \\
(70.4)\end{array}$ & $\begin{array}{c}567 \\
(79.5)\end{array}$ & $\begin{array}{c}585 \\
(77.2)\end{array}$ & $\begin{array}{c}586 \\
(64.4)\end{array}$ \\
\hline Streamed & Low & 60 & $\begin{array}{c}432 \\
(97.8)\end{array}$ & $\begin{array}{c}418.6 \\
(91.6)\end{array}$ & $\begin{array}{c}447.4 \\
(82.2)\end{array}$ & $\begin{array}{c}432 \\
(64.3)\end{array}$ & $\begin{array}{c}414.6 \\
(69.4)\end{array}$ \\
\hline
\end{tabular}

\section{Research Question One: Student Effect - Streamed and Non-Streamed Classes}

The proficiency level of streamed and unstreamed students differed (Table 1). Therefore, to ensure a fair comparison between the two groups, the suspected covariate of proficiency was partialed out of the results through the use of a MANCOVA. Students' overall proficiency test scores were used as the measure of proficiency. The data from the ten questionnaire items was found to meet the assumptions of normality, multicollinearity, and homogeneity of variance-covariance matrices.

The MANCOVA was undertaken with stream (streamed or non-streamed) as the independent variable and the questionnaire items as the dependent variable. Adjustment was made for the covariate of proficiency. Results from this analysis indicated a statistically significant multivariate effect based on stream, Wilks' $\lambda=0.740, F(10,230)=8.09, p<.001$, and around a quarter of the variability in the responses to the items could be accounted for by the independent variable, partial $\eta^{2}=.23$.

Summaries of the ten questionnaire items are shown in Table 2. The results from Item 1 showed that, on average, streamed students considered there to be less difference between their ability and their classmates' proficiency than unstreamed learners, $F(1,239)=15.305, p<.001$, partial $\eta^{2}=.06$. 


\section{Table 2}

\section{Comparisons Between the Streamed and Non-Streamed Groups}

\begin{tabular}{|l|c|c|c|}
\hline Questionnaire Items & Streamed & Non-Streamed & $t$ \\
\hline $\begin{array}{l}\text { 1. In my class, English levels are similar to mine } \\
\text { English at a high level }\end{array}$ & 2.48 & 2.79 & $3.91^{* * *}$ \\
\hline $\begin{array}{l}\text { 3. Having stronger classmates motivates me to work } \\
\text { harder }\end{array}$ & 1.61 & 2.67 & $2.52^{*}$ \\
\hline $\begin{array}{l}\text { 4. With the lower proficiency students in class, I } \\
\text { don't need to use a katakana accent to be } \\
\text { understood }\end{array}$ & 2.04 & 2.22 & $2.19^{*}$ \\
\hline $\begin{array}{l}\text { 5. I often help students through explanations } \\
\text { 6. With the lower proficiency students in class, I } \\
\text { don't need to give explanations in Japanese as } \\
\text { they understand my English explanations }\end{array}$ & 2.43 & 2.53 & -1.07 \\
\hline 7. I can understand the classroom materials & 2.89 & $5.30^{* * *}$ \\
\hline $\begin{array}{l}\text { 8. I can understand what my classmates are saying } \\
\text { preference (3) a mixed class }\end{array}$ & 1.82 & 1.94 & $2.18^{*}$ \\
\hline $\begin{array}{l}\text { 9. The class is appropriate for my level of English } \\
\text { 10. I would prefer to be in: (1) a streamed class (2) no }\end{array}$ & 2.03 & 2.20 & $2.14^{*}$ \\
\hline
\end{tabular}

Note: ${ }^{\star} p<.05,{ }^{\star \star} p<.01,{ }^{\star * \star} p<.001$

In Table 2, Items 2 and 3 pertain to the motivational level of the learners. The results for Item 2 show a statistically significant difference in how hard students reported pushing themselves to speak English. Streamed students considered that they tried harder to speak English well than unstreamed learners, $F(1,239)=6.342, p<.05$, partial $\eta^{2}=.03$. On the other hand, there was not found to be a statistically significant difference in how motivated the two groups of learners were by their stronger classmates $(p=.229)$.

Items 4, 5, and 6 related to learner-to-learner interaction. For Item 4, in the use of a katakana accent, streamed learners reported less need to simplify their pronunciation for intelligibility than unstreamed students, $F(1,239)=4.775, p<.05$, partial $\eta^{2}=.02$. For Item 5 , no statistically significant difference was found in the responses of the two groups for the frequency that they perceived helping other students through explanations $(p=.287)$. However, for Item 6 , streamed students felt less need to deliver these explanations through Japanese, $F(1,239)=$ 28.106, $p<.001$, partial $\eta^{2}=.11$.

Items 7 and 8 focused upon the students' ability to participate in streamed and mixed ability classes. Students in streamed classes were found to be better able to understand both the classroom materials (Item 7), $F(1,239)=4.744, p<.05$, partial $\eta^{2}=.02$, and their peers (Item 8), $F(1,239)=4.585, p<.05$, partial $\eta^{2}=.02$, albeit that there was only a small effect size.

The last two questions sought to shed light on learners' satisfaction with their streamed or unstreamed learning experience. Results for Item 9 indicated that tracked students felt that their class was more appropriate for their abilities, $F(1,239)=5.686, p<.05$, partial $\eta^{2}=.02$. However, when asked about the type of class they would prefer, a clear difference existed 
between the two groups, $F(1,239)=23.771, p<.001$, partial $\eta^{2}=.08$. Since students adapt to their learning environments, this was not unexpected. Nevertheless, while streamed students showed a clear preference for a streamed class (streamed $72 \%$, no preference $11 \%$, mixed class $17 \%$ ), unstreamed learners were far more ambivalent (streamed $40 \%$, no preference $19 \%$, mixed class $41 \%)$.

\section{Research Question Two: Student Effect - Streamed High Band, Streamed Low Band, and Non-Streamed Classes}

To address research question two, three MANCOVA analyses were performed. In all cases, the data was found to meet the assumptions of normality, multicollinearity, and homogeneity of variance-covariance matrices. In the various statistical tests, the independent variables were low streamed classes, high streamed classes, and unstreamed classes, proficiency was the suspected covariate, and the ten questionnaire items were the dependent variables. With the use of the Wilks' criterion, a difference in overall attitudes on the questionnaire was found between low streamed students and unstreamed learners, Wilks' $\lambda=0.710, F(10,155)=6.319, p<.001$, partial $\eta^{2}=.29$; high band participants and unstreamed students, Wilks' $\lambda=0.684, F(10,170)=$ $7.841, p<.001$, partial $\eta^{2}=.32$; and low and high band learners, Wilks' $\lambda=0.832, F(10,123)=$ $2.49, p<.01$, partial $\eta^{2}=.17$.

The various univariate results are contained in Table 3. As was the case for Table 2, the mean responses and contrasts have been adjusted to take into account the removal of the suspected covariate of proficiency. A comparison between streamed (low band) and unstreamed participants revealed four statistically significant differences. Compared to unstreamed students, low streamed learners reported that their classmates were of a closer ability to themselves for Item $1, F(2,164)=27.476, p<.001$, partial $\eta^{2}=.14$; for Item 6 , low streamed learners also indicated that they were less likely to resort to Japanese explanations, $F(2,164)=4.131, p$ $<.05$, partial $\left.\eta^{2}=.03\right)$; and were better able to understand their classmates (Item 8), $F(2,164)=$ $5.456, p<.05$, partial $\eta^{2}=.03$. Low streamed students also had a different perception of the type of class that would best suit them (Item 10), $F(2,164)=15.532, p<.001$, partial $\eta^{2}=.09$. When asked about the type of English class they would prefer, low streamed learners indicated a clear preference for a streamed learning environment (streamed $67 \%$, no preference $10 \%$, unstreamed $23 \%$ ). 
Table 3

Comparisons between High Stream, Low Stream and Non-Streamed Groups

\begin{tabular}{|c|c|c|c|c|c|}
\hline \multirow{3}{*}{ Questionnaire Item } & \multicolumn{3}{|c|}{ Mean Responses } & \multicolumn{2}{|c|}{ Comparisons } \\
\hline & \multicolumn{2}{|c|}{ Streamed } & \multirow{2}{*}{ Unstreamed } & \multirow{2}{*}{$\begin{array}{c}\text { Unstreamed/ } \\
\text { Streamed Low } \\
t \text { score }\end{array}$} & \multirow{2}{*}{$\begin{array}{c}\text { Unstreamed/ } \\
\begin{array}{c}\text { Streamed } \\
\text { High }\end{array} \\
t \text { score }\end{array}$} \\
\hline & Low & High & & & \\
\hline $\begin{array}{l}\text { 1. In my class, English } \\
\text { levels are similar to } \\
\text { mine }\end{array}$ & 2.23 & 2.69 & 2.78 & $5.27^{* * *}$ & .79 \\
\hline $\begin{array}{l}\text { 2. With classmates, I'm } \\
\text { pushing myself to use } \\
\text { English at a high level }\end{array}$ & 2.61 & 2.30 & 2.68 & .58 & $3.24^{* * *}$ \\
\hline $\begin{array}{l}\text { 3. Having stronger } \\
\text { classmates motivates me } \\
\text { to work harder }\end{array}$ & 1.68 & 1.54 & 1.71 & .25 & 1.57 \\
\hline $\begin{array}{l}\text { 4. With the lower } \\
\text { proficiency students in } \\
\text { class, I don't need to use } \\
\text { a katakana accent to be } \\
\text { understood }\end{array}$ & 2.36 & 1.75 & 2.23 & -1.18 & $4.60^{* * *}$ \\
\hline $\begin{array}{l}\text { 5. I often help students } \\
\text { through explanations }\end{array}$ & 2.24 & 2.78 & 2.42 & 1.63 & $-3.27^{* * *}$ \\
\hline $\begin{array}{l}\text { 6. With the lower } \\
\text { proficiency students in } \\
\text { class, I don't need to } \\
\text { give explanations in } \\
\text { Japanese as they } \\
\text { understand my English } \\
\text { explanations }\end{array}$ & 2.64 & 2.23 & 2.90 & $2.25^{*}$ & $5.89 * * *$ \\
\hline $\begin{array}{l}\text { 7. I can understand the } \\
\text { classroom materials }\end{array}$ & 1.80 & 1.73 & 1.92 & 1.26 & $2.02 *$ \\
\hline $\begin{array}{l}\text { 8. I can understand what } \\
\text { my classmates are } \\
\text { saying }\end{array}$ & 1.74 & 1.89 & 1.96 & $2.40^{*}$ & .84 \\
\hline $\begin{array}{l}\text { 9. The class is appropriate } \\
\text { for my level of English }\end{array}$ & 2.14 & 1.92 & 2.21 & .67 & $2.98^{* *}$ \\
\hline $\begin{array}{l}\text { 10. I would prefer to be in: } \\
\text { (1) a streamed class } \\
\text { (2) no preference } \\
\text { (3) a mixed class }\end{array}$ & 1.37 & 1.56 & 1.98 & $4.34^{* * *}$ & $3.04^{* *}$ \\
\hline
\end{tabular}

Note: ${ }^{\star} p<.05,{ }^{\star \star} p<.01,{ }^{\star \star \star} p<.001$

When comparing high band streamed students and non-streamed learners, a larger number of statistically significant differences was found between the two groups. The streamed group reported that they were more motivated (Item 2$), F(2,179)=11.583, p<.001$, partial $\eta^{2}=.06$. However, when it came to learner to learner interaction, results were mixed. While high band streamed students were less likely to resort to a katakana accent (Item 4), $F(2,179)=17.655, p$ $<.001$, partial $\eta^{2}=.09$, and felt less need to give explanations in Japanese (Item 6$), F(1,179)=$ 28.864, $p<.001$, partial $\eta^{2}=.14$, for Item 5 , they reported providing fewer explanations than non-streamed learners, $F(1,179)=11.583, p<.001$, partial $\eta^{2}=.06$. 
In terms of classroom participation, while no meaningful difference was found in the reported ability of high stream students and unstreamed learners to understand their classmates for Item 8 $(p=.400)$, for Item 7 , the streamed group were found to understand the classroom materials better than their non-streamed counterparts, $F(1,179)=4.103, p<.05$, partial $\eta^{2}=.02$.

For Item 9, high stream students also expressed greater satisfaction than unstreamed learners that their class was appropriate for them, $F(1,179)=6.565, p<.01$, partial $\eta^{2}=.04$. While there was relatively little difference in the proportion of students from these groups that expressed a positive sentiment about the appropriateness of their class (high streamed, $83 \%$; unstreamed, $77 \%$ ), a far greater proportion of streamed learners strongly agreed that their class was suitable (high streamed, 23\%; unstreamed, 4\%).

Lastly, as expected, the responses for Item 10 show high stream learners had a different perception of their ideal class environment from unstreamed learners, $F(1,179)=5.806, p$ $<.05$, partial $\eta^{2}=.03$. However, as was noted in relation to research question one, while unstreamed students were collectively unsure of their preferred classroom style, high stream learners expressed a strong preference for a streamed class (streamed $76 \%$, no preference $12 \%$, mixed class $12 \%)$.

\section{Discussion}

The results from this study show that, even after the removal of the influence of proficiency, differences in the overall attitudes of streamed and unstreamed students towards a range of classroom issues existed. The MANCOVA results also revealed differences between the classroom perspectives of streamed low-proficiency and streamed high-proficiency learners, and unstreamed students.

\section{Socio-Affective Effects}

Despite the placement procedures of the two departments not being announced to the students, in terms of English proficiency, streamed learners perceived that they were much more similar to their classmates than the results reported by non-streamed students. In the streamed department, it was hoped that by not discussing the placement procedure and students' level of proficiency with the learners, any feelings of inferiority amongst the students in lower-proficiency classes and of superiority amongst top tier students would be diminished. However, the current results seem to indicate that students independently develop an awareness of their ability in relation to that of their classmates. Therefore, while there would seem to be limited benefit in concealing the placement procedure, by not revealing the program's mission and procedures, the chance to clearly explain the rationale behind streaming is lost. Through such discussion in mixed-ability classes, teachers can set clear expectations for learner-learner collaboration and peer tutoring, provide strategy instruction, and invite students to provide feedback about their learning experiences (see Brown, 2009; Mathews-Aydinli \& van Horne, 2006). In addition, if students have a clear idea of their proficiency level and realize that L2 learning is incremental (Murphey \& Arao, 2001), teachers can help them set achievable goals and maintain a positive, yet realistic self-concept.

The results from Item 2 show the streamed learners, particularly the higher proficiency group, are pushing themselves more to use English at a high level than their non-streamed counterparts. There is a suggestion from this result that the BFLP effect is not operating as a demotivator in the streamed classes. In fact, particularly within the higher streamed classes, the findings suggest that the students tended to view their slightly stronger classmates as peer role models who they seek to emulate. Furthermore, the fact that higher-proficiency unstreamed students do not have as much opportunity to interact with similar or higher-proficiency peers may contribute to why 
they feel that they are "pushing" themselves less than the streamed learners. Conversely, within the same unstreamed classes, due to linguistic or topic difficulty, lower-proficiency students who are working with much stronger peers may be contributing little during pair or group discussions.

\section{Learner-Learner Interaction}

To a statistically significant degree, once the proficiency covariate had been removed, non-streamed learners reported giving more explanations to classmates than high-proficiency streamed learners; this is as one might expect, since there would be more lower-proficiency learners in mixed-ability classes who would require assistance. However, lower-proficiency students in streamed classes reported giving the most help of all, lending support to the idea that that there is enough variation left within streamed classes to allow for peer assistance (Mills et al., 1996).

Streamed students reported being less likely than their non-streamed counterparts to use a katakana accent to facilitate communication with classmates. This was especially true of the streamed high-proficiency learners. The use of a katakana pronunciation refers to the enunciation of English words with a strong Japanese accent. While this method of articulation sometimes renders speech more understandable to Japanese students, the use of a katakana accent greatly reduces the intelligibility of English to non-Japanese natives. The reasons why high proficiency streamed students feel less need to use katakana-style English pronunciation are likely to relate to them being more confident that their classmates will be able to understand native-like English pronunciation and that among their higher proficiency peers, a native-like English accent is more socially acceptable. On the other hand, learners in non-streamed classes more often felt the need to use katakana pronunciation to make themselves understood by their classmates and perhaps also to reaffirm their place as members of their L1 peer group (Walqui, 2000; Lefkowitz \& Hedgcock, 2002). The results suggest that the conditions for practicing pronunciation may not be as favorable for non-streamed high-proficiency students as for their counterparts in more homogeneous classes.

While a significant percentage of students in all groups acknowledged that they sometimes needed to use Japanese to "lubricate" (Butzkamm, 1998) exchanges with their lower-proficiency classmates, the non-streamed students reported a statistically significant greater use of the L1 than either of the streamed learning groups. Thus, it may be unrealistic for teachers to expect students with large differences in proficiency to always stay in the TL when students are expected to assist their weaker classmates. Furthermore, some higher-proficiency students in non-streamed classes who would prefer to use English as much as possible may feel frustrated by these higher levels of L1 use.

The streamed students reported being better able to understand the classroom learning materials, and despite the removal of proficiency as a confounding factor, the high-proficiency learners reported understanding the materials best of all. The streamed students' superior understanding is likely to reflect their instructors' ability to tailor classroom tasks and materials to the students' more uniform proficiency level. Interestingly, the lower-proficiency streamed students reported the least difficulty in understanding their classmates. Since the class is streamed, it is logical that the students are producing utterances at a level that would be comprehensible to their peers, whereas in non-streamed classes, higher-proficiency students would be more likely to produce advanced-level vocabulary and grammatical structures, which lower-proficiency students would likely struggle to understand. However, while the high stream students reported greater comprehension of their classmates than the non-streamed students, no statistically significant difference was found between the two groups. The existence of a meaningful difference 
between the low stream and the unstreamed students, but the lack of such a meaningful difference between the high stream and the unstreamed learners may reflect the wider range of spoken proficiency in the more advanced streamed classes ( $S D=77.2)$ compared to the lower streamed groups (64.3).

\section{Class Preference}

The streamed students agreed more strongly than the unstreamed learners that the level of their class was appropriate for their level of English skills. Moreover, high-proficiency streamed students were especially satisfied with their class level compared to the non-streamed students. By combining the results for questionnaire Items 2, 4, 6, and 7, compared to streamed learners, it can be speculated that higher-proficiency unstreamed students tended to feel that they were less sufficiently challenged in a mixed-ability class, while lower-proficiency students in unstreamed groups perhaps tended to regard their class as overly difficult. Lastly, while streamed students expressed a clear desire to be part of a streamed class, non-streamed learners were far more ambivalent about their preferred placement method.

\section{Conclusion}

The findings from this study suggest that there are several advantages to streaming for both lower and higher-proficiency students. However, it is also worth recognizing that teachers often have little say in placement decisions. Teachers who find themselves teaching either streamed or mixed-ability classes can teach collaborative skills to help maximize the benefits of cooperative learning in support of L2 acquisition; indeed, without learner training, effective peer collaboration may not take place (e.g., Gobel, 2006). When teaching classes that have a wide range of proficiencies, teachers can try to ensure that all students are appropriately challenged by employing a differentiated approach, adjusting the content of activities, the learning process, or expectations regarding the final product (Burris \& Garrity, 2008). However, numerous studies have demonstrated that "teachers do not find differentiation easy to implement or sustain" (Westwood \& Arnold, 2004, p. 375). Following Murphey and Arao (2001), teachers may want to guide students in choosing more proficient learners to serve as role models or comparison targets. Where classes are streamed, classes of different levels can be regularly combined to encourage peer assistance and minimize any possible negative effects of streaming. Finally, teachers should recognize that groups that have a wide range in proficiencies may have more need to use shared L1 resources (Mathews-Aydinli \& van Horne, 2006; Swain \& Lapkin, 2000). Through awareness of student perceptions and potential problems, teachers can help students to have positive and effective learning experiences, whether in streamed or mixed-ability classes.

\section{Biodata}

Paul Joyce teaches at Kinki University in Osaka, Japan. His research interests include L2 vocabulary acquisition, L2 listening, and language testing.

Brian McMillan is currently teaching at Hiroshima Bunkyo Women's University. His research interests include motivation, learner-learner interaction, and the use of the L1 in L2 learning. 


\section{References}

Ansalone, G. (2003). Poverty, tracking, and the social construction of failure: International perspectives on tracking. Journal of Children \& Poverty, 9(1), 3-20. http://dx.doi.org/10.1080/1079612022000052698

Bonk, W. J. (2001). Predicting paper-and-pencil TOEFL scores from KEPT data. Kanda University of International Studies Research Institute of Language Studies and Language Education Working Papers, 12, 65-86.

Brown, A. V. (2009). Students' and teachers' perceptions of foreign language teaching: A comparison of ideals. The Modern Language Journal, 93(1), 46-60. http://dx.doi.org/10.1111/j.1540-4781.2009.00827.x

Burris, C. C., \& Garrity, D. T. (2008). Detracking for excellence and equity. Alexandria, VA: Association for Supervision and Curriculum Development.

Butzkamm, W. (1998). Code-switching in a bilingual history lesson: The mother tongue as a conversational lubricant. International Journal of Bilingual Education and Bilingualism, 1(2), 81-99. http://dx.doi.org/10.1080/13670059808667676

Dai, D. Y., \& Rinn, A. N. (2008). The big-fish-little-pond effect: What do we know and where do we go from here? Educational Psychology Review, 20(3), 283-317. http://dx.doi.org/10.1007/s10648-008-9071-x

Dörnyei, Z., \& Murphey, T. (2003). Group dynamics in the language classroom. Cambridge, England: Cambridge University Press.

Eckerth, J. (2009). Negotiated interaction in the L2 classroom. Language Teaching, 42(1), 109-130. http://dx.doi.org/10.1017/S0261444808005442

Gillis-Furutaka, A., \& Sakurai, N. (2002). Curriculum change and streaming in the department of English at Kyoto Sangyo University. Curriculum Innovation, Testing and Evaluation: Proceedings of the 1st Annual JALT Pan-SIG Conference, 116-120. Retrieved from http://jalt.org/pansig/2002/HTML/GFS.htm

Gobel, P. (2006). Dealing with learning style conflicts in the cooperative learning classroom. IASCE Newsletter, 25(2), 2-7. Retrieved from http://www.iasce.net/Newsletters/2006_June/2006_jun_3.shtml

Jones, J., Harris, A. C., \& Putt, G. D. (1990). Streaming in first-year university classes. Studies in Higher Education, 15(1), 21-30. http://dx.doi.org/10.1080/03075079012331377571

Lefkowitz, N., \& Hedgcock, J. (2002). Sound barriers: Influences of social prestige, peer pressure and teacher (dis)approval on FL oral performance. Language Teaching Research, 6(3), 223-244. http://dx.doi.org/10.1191/1362168802/r107oa

Lesser, M. J. (2004). Learner proficiency and focus on form during collaborative dialogue. Language Teaching Research, 8(1), 55-81. http://dx.doi.org/10.1191/1362168804Ir134oa

Liu, W. C., Wang, C. K. J., \& Parkins, E .J. (2005). A longitudinal study of students' academic self-concept in a streamed setting: The Singapore context. British Journal of Educational Psychology, 75(4), 567-586. http://dx.doi.org/10.1348/000709905X42239

Marsh, H. W. (1987). The big-fish-little-pond effect on academic self-concept. Journal of Educational Psychology, 79(3), 280-295. http://dx.doi.org/10.1037/0022-0663.79.3.280

Mathews-Aydinli, J., \& van Horne, R. (2006). Promoting the success of multilevel ESL classes: What teachers and administrators can do. Washington, DC: Center for Adult English Language Acquisition. Retrieved from http://www.literacyminnesota.org/sites/6bc90f8a-e528-403a-8c6b-ffdd2e3dd3a7/uploa ds/promo.pdf

Mills, A., Swain, L., \& Weschler, R. (1996). The implementation of a first year English placement system. The Internet TESL Journal, 2(11). Retrieved from http://iteslj.org/Articles/Mills-Placement.html 
Murphey, T., \& Arao, H. (2001). Reported belief changes through near peer role modeling. TESL-EJ, 5(3), 1-15. Retrieved from http://tesl-ej.org/ej19/a1.html

Storch, N. (2001). How collaborative is pair work? ESL tertiary students composing in pairs. Language Teaching Research, 5(1), p. 29-53. http://dx.doi.org/10.1177/136216880100500103

Swain, M., \& Lapkin, S. (2000). Task-based second language learning: The uses of the first language. Language Teaching Research, 4(3), 251-274. http://dx.doi.org/10.1177/136216880000400304

Walqui, A. (2000). Contextual factors in second language acquisition. ERIC Digest. Center for Applied Linguistics. Retrieved from http://www.cal.org/resources/digest/0005contextual.html

Watanabe, Y. (2008). Peer-peer interaction between L2 learners of different proficiency levels: Their interactions and reflections. The Canadian Modern Language Review, 64(4), 605-635. http://dx.doi.org/10.1353/cml.0.0008

Westwood, P., \& Arnold, W. (2004). Meeting individual needs with young learners. ELT Journal, 58(4), 375-378. http://dx.doi.org/10.1093/elt/58.4.375 


\section{Appendix \\ Student Effect Questionnaire (English)}

Name:

Student number:

This survey is part of a research project looking at how students work together in class.

1) In my class, most students' English skills are similar to mine.

strongly agree agree disagree strongly disagree

2) When working with my classmates, I feel that I'm pushing myself to use my English skills at a high level.

strongly agree agree disagree strongly disagree

3) Having students in my class whose English skills are stronger than mine motivates me to work harder.

strongly agree agree disagree strongly disagree

4) With the lower proficiency students in class, I don't need to use a katakana accent to be understood.

strongly agree agree disagree strongly disagree

5) I often help my classmates by explaining things to them.

strongly agree agree disagree strongly disagree

6) With the lower proficiency students in class, I don't need to give explanations in Japanese as they understand my English explanations.

strongly agree agree disagree strongly disagree

7) I can understand the classroom materials.

strongly agree agree disagree strongly disagree

8) I can clearly understand what my classmates are saying.

strongly agree agree disagree strongly disagree

9) I feel that the level of my class is appropriate for the level of English skills I have. strongly agree agree disagree strongly disagree

10) If I could choose, I would prefer to be ...

$\square$ in a class with students whose English skills are about the same level as mine

$\square$ I don't have a preference either way

$\square$ in a mixed-level class, with some students having more advanced level English skills and others having intermediate or beginner level English skills

11) Do you have any other comments you would like to share about your English skill level, your class, or any of the questions in this survey? 